\title{
Preparations of Methylphenyldiethoxsilane by One Step Grignard Method and Methylphenylcyclosiloxane by Hydrolysis and Pyrolysis Methods

\author{
Min $\mathrm{LI}^{1, \mathrm{a}}$, Liu-Meng $\mathrm{CHEN}^{2, \mathrm{~b}}$, Bo-Quan JIANG ${ }^{1, \mathrm{C}^{*}}$ \\ ${ }^{1}$ Department of Biology Chemistry, Institute of Science, Nanchang University College of Science \\ and Technology, Nanchang, Jiangxi, 330029, P.R.China
} \\ ${ }^{2}$ Institute of Applied Agricultural Microorganism, Jiangxi Academy of Agricultural Science, Nanchang, Jiangxi, 330200, China \\ a34380737@qq.com, b13931409@qq.com, cjbq_win@163.com \\ ${ }^{*}$ Corresponding author
}

Keywords: Methyl Phenol Cyclic Silicone, Methyl Phenyl Diethoxy Silane, Grignard Method, Hydrolysis, Pyrolysis.

\begin{abstract}
Methyl phenol cyclic silicone (MPCS) and methyl phenyl diethoxy silane (MPDS) are important materials for production of addition-cured liquid silicone rubber. The one step Grignard method was used to synthesize MPDS and the orthogonal test method was applied to optimize the process. The maximum MPDS yield of $60.2 \%$ was obtained under molar ratio of magnesium/ methyl triethoxy silane/chlorobenzene of $1 / 1.5 / 1.25$, reaction time of $2.5 \mathrm{~h}$ and reaction temperature of $95^{\circ} \mathrm{C}$. The hydrolysis and pyrolysis methods were used to synthesize MPCS and the single factor method was applied to optimize the process. The maximum MPCS yield of $72 \%$ was achieved with DBS/MPDS mass ratio of $4 \%$ and fractional addition of MPDS at $95^{\circ} \mathrm{C}$. The products were characterized by infrared spectrometer and the results showed that the peaks appeared on the IR spectra were basically in agreement with those of MPDS and MPCS, respectively.
\end{abstract}

\section{Introduction}

Methyl phenol cyclic silicone (MPCS) refers to the ring silicone containing both methyl and phenyl on a silicon atom and its structure general formula can be simply expressed as $(\mathrm{CH} 3 \mathrm{PhSiO}) \mathrm{n}$ $(\mathrm{n}>3$ )[1].MPCS is an important raw material to prepare high performance poly methyl phenyl silicone materials. In China, the traditional preparation of MPCS uses methyl phenyl dichlorosilan as raw material by thermal condensation method[2-4]. The main byproduct formed by this method is phenyl trichlorosilane, which is very difficultly separated due to its boiling point close to that of methyl phenyl dichlorosilan. Therefore, the methyl phenyl dichlorosilane produced by thermal condensation method is difficulty applied to the production of linear poly methyl phenyl silicone, which greatly limits its application. Difunctional organic alkoxy silane, such as methyl phenyl diethoxy silane( MPDS), can be used to produce ring silicone and linear polysiloxane with acids, alkalis, salts or metal oxides as catalysts by hydrolytic condensation method[5]. The addition of inert solvent, ethanol or surfactant during the hydrolysis is conductive to the formation of ring silicone and linear polysiloxane. MPDS is an important synthesis monomer for producing methyl phenyl cyclic siloxane, methyl phenyl vinyl raw rubber and addition-cured liquid silicone rubber. There are only a few plants for the production of MPDS and MPDS is mainly imported in China. The detailed study on MPDS is rarely reported in literature. Therefore, it is significant to deeply study the preparation and application of MPDS. In this paper, The one step Grignard technical route was used to synthesize MPDS and then the synthesized MPDS was used to prepare MPCS by hydrolysis and pyrolysis methods. The main attentions were paid to the process optimization and product characterizations. 


\section{Experimental}

\section{Synthesis of MPDS}

Experimental Principle and Method. The one step Grignard technical route was used to synthesize MPDS by direct reaction of methyl triethoxy silane (MTS) with magnesium and chlorobenzene $(\mathrm{CB})$. The reaction formula is as follows:

\section{$\mathrm{CH}_{3} \mathrm{Si}(\mathrm{OEt})_{3}+\mathrm{PhCl}+\mathrm{Mg} \longrightarrow \mathrm{CH}_{3} \mathrm{PhSi}(\mathrm{OEt})_{2}+\mathrm{Mg}(\mathrm{OEt}) \mathrm{Cl}$}

The experiment was carried out by orthogonal test method.

Synthesis Procedure. $3.6 \mathrm{~g}$ magnesium, $15 \mathrm{ml}$ methyl triethoxy silane, $7 \mathrm{ml}$ chlorobenzene and 1-2 grain of iodine were added into a $250 \mathrm{ml}$ four necks flask to be heated for triggering the initiation reaction.As from $110{ }^{\circ} \mathrm{C}$, the stirring and backflow were started. When the purple gradually disappeared with increasing temperature until $155^{\circ} \mathrm{C}$, the liquid mixture of methyl triethoxy silane and chlorobenzene was added into the flask within $1 \mathrm{~h}$ and then continue to react for 2-4h. After reaction, the mixture was filtered for separating the excess methyl triethoxy silane at normal pressure and then collected $145 \sim 147{ }^{\circ} \mathrm{C}$ fractions with vacuum distillation(10 kpa).

\section{Synthesis of MPCS}

Experimental Principle and Method. The hydrolysis and pyrolysis methods were used to synthesize methylphenylcyclosiloxane (MPCS) with methyl phenyl diethoxsilane as reactant, dilute sulphuric acid as catalyst and sodium dodecyl benzene sulfonate (DBS) as surfactant. The formula is as follows:

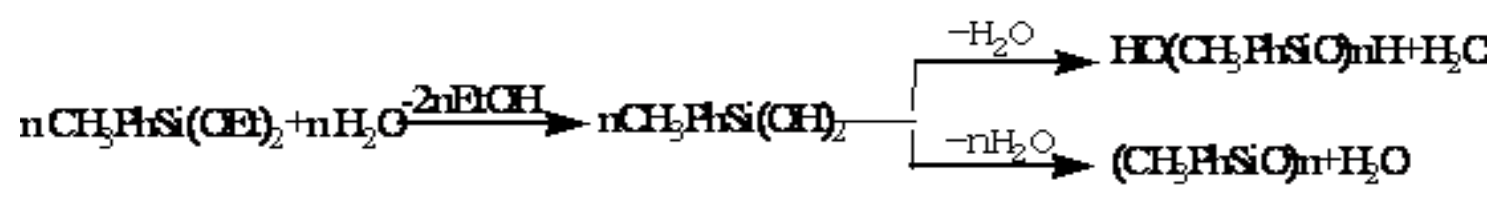

The experiment was carried out by single factor method.

Synthesis Procedure. 5\% dilute sulphuric acid with 2 times of MPDS mass was first added in a three necks flask followed an addition of certain amount of DBS. The mixture was heated up to $95{ }^{\circ} \mathrm{C}$ with stirring and then MPDS was fractionally added for a hydrolysis reaction of $4 \mathrm{~h}$. After reaction, the ethanol was distilled and the water layer was separated. The oil phase was neutralized by adding a certain amount of sodium carbonate. The hydrolysate was washed by distilled water and dried for $3 \mathrm{~h}$ at $90^{\circ} \mathrm{C}$ after the residual moisture was stressed out. The pyrolysis with the residual sodium carbonate as catalyst was carried out under vacuum at $240-280{ }^{\circ} \mathrm{C}$, and the fractions of $160^{\circ} \mathrm{C}-200^{\circ} \mathrm{C} / \mathrm{mmHg}$, a transparent methyl phenyl cyclic silicone, was collected.

\section{Results and Discussions}

\section{Optimization of MPDS}

Molar ratio of $\mathrm{Mg} / \mathrm{MTS} / \mathrm{CB}(\mathrm{CB}$ as valuable), Mole ratio of $\mathrm{Mg} / \mathrm{MTS} / \mathrm{CB}$ (MTS as valuable), reaction time and reaction temperature were taken as investigation factors. The orthogonal experiment with four factors/three levels $\left(\mathrm{L}_{9}\left(3^{4}\right)\right)$ was designed and the results are shown in Table 1.

It can be seen from Tab. 1 that the relative size of the effects of the four factors on the yield is $\mathrm{B}, \mathrm{A}, \mathrm{C}$ and $\mathrm{D}$ due to $R_{K, \mathrm{~B}}>R_{K, \mathrm{~A}}>R_{K, \mathrm{C}}>R_{K, \mathrm{D}}$ and the optimum level group is $\mathrm{A}_{2} \mathrm{~B}_{2} \mathrm{C}_{2} \mathrm{D}_{2}$ according to the maximum $K_{\mathrm{i}}$ values of each factor. However the level group of $\mathrm{A}_{2} \mathrm{~B}_{2} \mathrm{C}_{2} \mathrm{D}_{2}$ is not found in 
Table 1, so three parallel tests were added and the results showed that the average yield was $60.2 \%$, which is more than that of $\mathrm{A}_{2} \mathrm{~B}_{2} \mathrm{C}_{3} \mathrm{D}_{1}(41.0 \%)$ in Table1.Therefore, the optimum conditions were determined as follows: molar ratio of $\mathrm{Mg} / \mathrm{MTS} / \mathrm{CB} 1 / 1.5 / 1.25$, reaction time $2.0 \mathrm{~h}$ and reaction temperature $155^{\circ} \mathrm{C}$.

Tab.1 Design and results of orthogonal experiment $\left(\mathrm{L}_{9}\left(3^{4}\right)\right)$

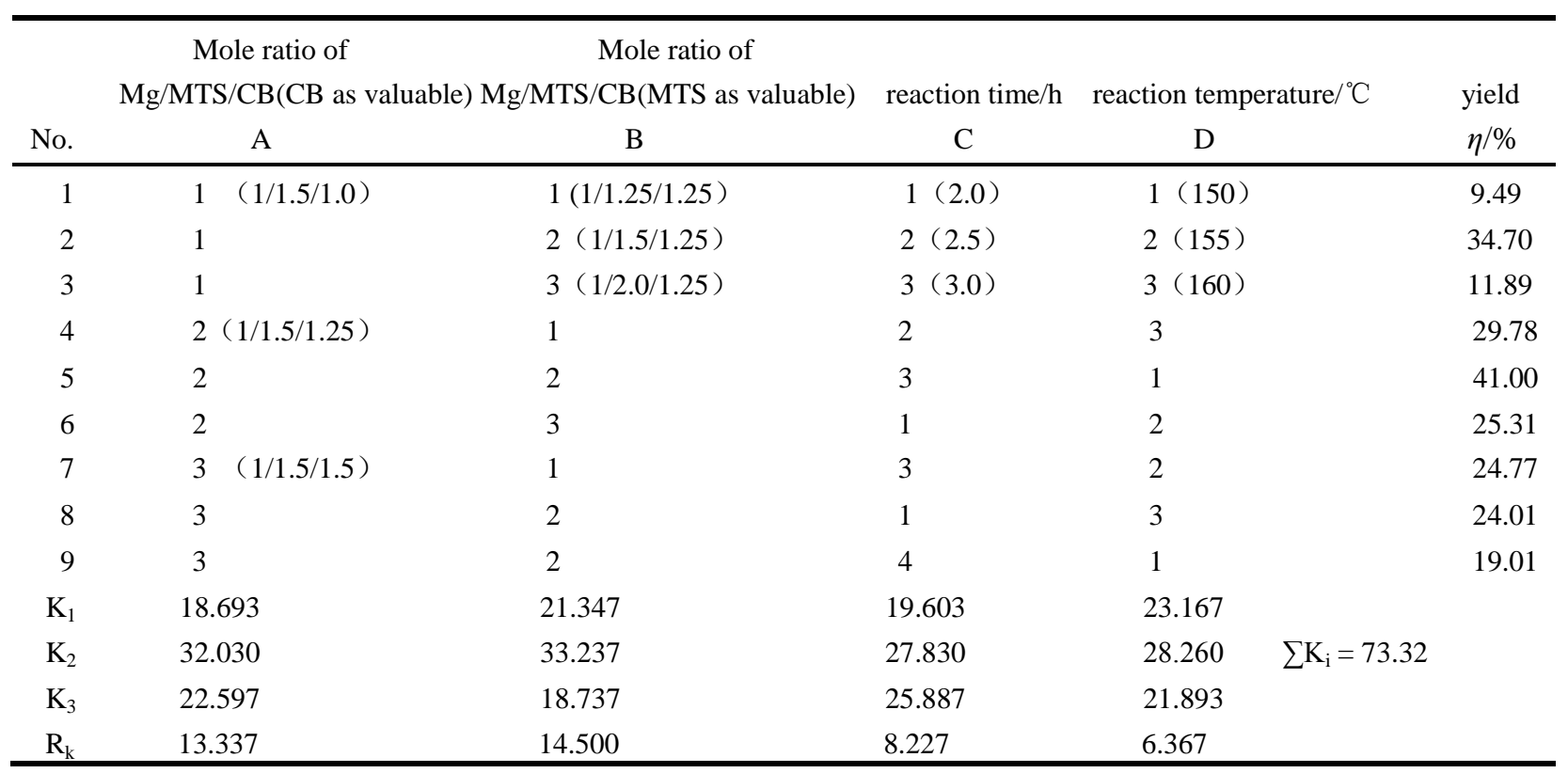

The variance analysis of the orthogonal experiment is shown in Table 2.The purpose of variance analysis is to determine the significance level of each factor[6]. It is found from Table 2, that all the four factors are not significant, however the relative size of their effects on the yield are factor $\mathrm{B}, \mathrm{A}, \mathrm{C}$ and $\mathrm{D}$ according to $\mathrm{F}_{\mathrm{i}}$ values.

Tab.2 Variance analysis of orthogonal experiment $\left(\mathrm{L}_{9}\left(3^{4}\right)\right)$

\begin{tabular}{cccccc}
\hline $\begin{array}{c}\text { Variance } \\
\text { source }\end{array}$ & $\begin{array}{c}\text { Bias } \\
\text { squares }\end{array}$ & $\begin{array}{c}\text { Degree of } \\
\text { freedom }\end{array}$ & $\mathrm{F}_{\mathrm{i}}$ & $\mathrm{F}_{\alpha}(a=0.01,0.05,0.1)$ & $\begin{array}{l}\text { Significance } \\
\text { level }\end{array}$ \\
\hline $\mathrm{A}$ & 282.090 & 2 & 1.377 & $\mathrm{~F}_{0.01}=8650$ & Not significant \\
$\mathrm{B}$ & 358.434 & 2 & 1.749 & $\mathrm{~F}_{0.05}=4.460$ & Not significant \\
$\mathrm{C}$ & 110.935 & 2 & 0.541 & $\mathrm{~F}_{0.1}=3.110$ & Not significant \\
$\mathrm{D}$ & 68.098 & 2 & 0.332 & & Not significant \\
error & 819.56 & 8 & & & \\
\hline
\end{tabular}

\section{Infrared Spectrum of MPDS}

Fig.1 shows the infrared spectra (IR) of MPDS by Fourier Infrared Spectrometer (Nicolet 5700, US). From Fig. 1 we can see four $\mathrm{Si}-\mathrm{C}_{6} \mathrm{H}_{5}$ aromatic ring vibration absorption peaks at 1592, 1482, 1429 and $1482 \mathrm{~cm}^{-1}$, two $\mathrm{Si}-\mathrm{C}$ stretching vibration absorption peaks at 737 and $700 \mathrm{~cm}^{-1}$, two $\mathrm{CH}_{3}$ symmetry deformation vibration absorption peaks of $\mathrm{Si}-\mathrm{CH}_{3}$ at 1390 and $1259 \mathrm{~cm}^{-1}$, a Si-C stretching vibration absorption peak at $795 \mathrm{~cm}^{-1}, \mathrm{a} \mathrm{CH}_{3}$ rocking vibration absorption peak at 768 $\mathrm{cm}^{-1}$, three C-H stretching vibration absorption peaks of $\mathrm{Si}-\mathrm{OCH}_{2} \mathrm{CH}_{3}$ at 2970,2930 and $2880 \mathrm{~cm}^{-1}$, two $\mathrm{Si}-\mathrm{O}$ absorption peaks at 1259 and $1160 \mathrm{~cm}^{-1}$, and a Si-O-C telescopic shock absorption peak at $955 \mathrm{~cm}^{-1}$. These Characteristic peaks proved that the sample is methyl phenyl diethoxsilane. 


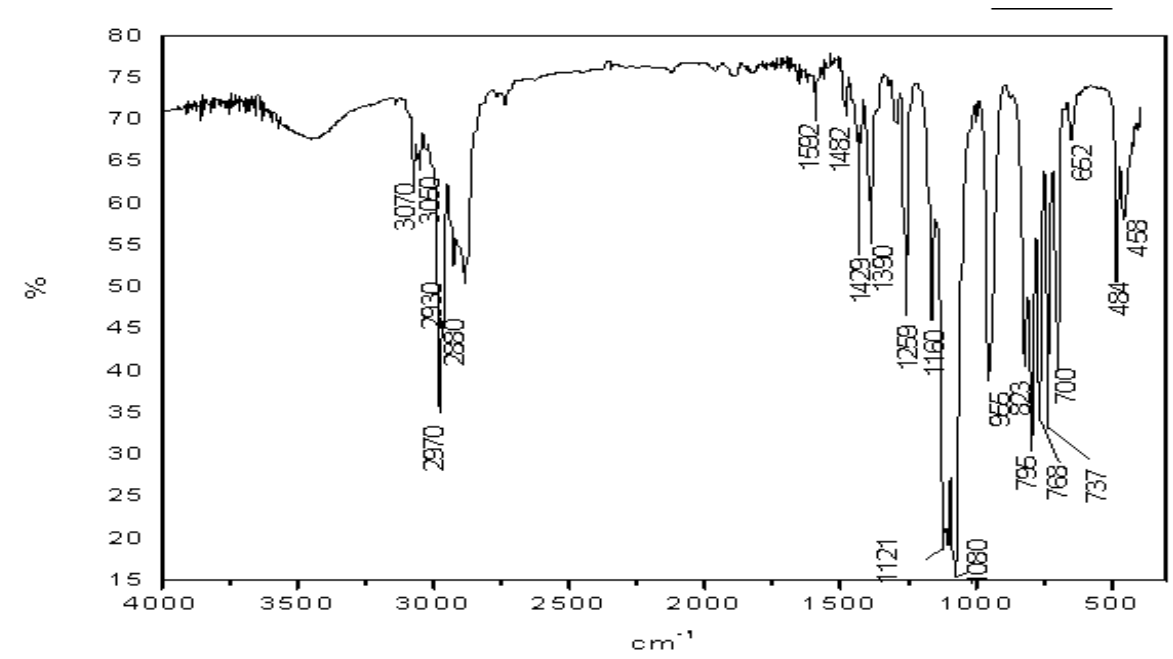

Fig.1. IR photograph of MPDS

\section{Optimization of MPCS}

Hydrolysis can generally be conducted in acid or alkaline medium. Under the joint action of acid and heat, the silicon alcohol generated by hydrolysis is dehydrated and condensed to cyclization siloxane and linear polysiloxane. It is very important to control the viscosity of hydrolysate in the process of hydrolysis. Higher viscosity means more linear polysiloxane and low cyclic siloxane yield, which results in a disproportionation reaction, crosslinking polymer, poor product quality and difficult scale-up. In order to optimize the reaction process, three key factors of hydrolysis medium, temperature and feeding manner were taken to be investigated.

Effect of Hydrolysis Medium. Ethanol, toluene and DBS are selected as medium for increasing the total yield of ring body. The results are shown in Tab.3.

Tab.3 Effects of different hydrolysis mediums on total yield of ring body (at $95^{\circ} \mathrm{C}$ )

\begin{tabular}{cccccc}
\hline Medium & $\begin{array}{c}\text { Mass ratio } \\
\text { medium/MPDS }\end{array}$ & $\begin{array}{c}\text { Total yield } \\
\text { of } \\
\text { ring body/\% }\end{array}$ & Medium & $\begin{array}{l}\text { Mass ratio } \\
\text { of } \\
\text { medium/MPDS }\end{array}$ & $\begin{array}{c}\text { Total yield of } \\
\text { ring body/\% }\end{array}$ \\
\hline ethanol & 200 & 44 & DBS & 1.7 & 50 \\
toluene & 200 & 46 & DBS & 3.3 & 62 \\
DBS & 0.4 & 44 & DBS & 4 & 72 \\
DBS & 0.6 & 49 & DBS & 4 & 72 \\
\hline
\end{tabular}

As seen from Tab.3, DBS has a largest effect on the total yield of ring body. The total yield of ring body increases with the addition amount of DBS and reaches the maximum value (72\%) with DBS/MPDS mass ratio of $4 \%$. Compared with DBC, the total yield of ring body with ethanol as medium is lower due to the low boiling point of ethanol. The total yield of ring body with toluene as medium is slightly higher than that of ethanol, but it is a poisonous solvent and difficultly be recovered.

Effect of Temperature. The effect of hydrolysis temperature on the total yield of ring body was investigated. The results showed that the total yield of ring body was increased with increasing temperature. The yield was less than $40 \%$ at low temperature due to incomplete reaction. The reaction was easily conducted and the total yield of ring body was higher when the temperature was over $90{ }^{\circ} \mathrm{C}$, however, the temperature should not be over $100{ }^{\circ} \mathrm{C}$ due to solvent evaporation. 
Effect of Feeding Manner. It was found in the experiment that the fractional addition of MPDS was better than one-time feeding manner because the former made the reaction process be smoothly conducted, increased the MPCS yield and obtained the product with lower viscosity.

Infrared Spectrum of MPCS. The IR photograph of MPCS is shown in Fig.2. It can be seen from Fig. 2 that the two methylene absorption peaks at $2880 \mathrm{~cm}, 2970 \mathrm{~cm}-1$, four Si-O-CH2-CH3 absorption peaks at $1160 \mathrm{~cm}-1,955 \mathrm{~cm}-1,1080 \mathrm{~cm}-1$ and $1121 \mathrm{~cm}-1$ (bimodal) of MPDS disappear but two ring siloxane Si-O-Si absorption peaks appear at $1122 \mathrm{~cm}-1$ and $1060 \mathrm{~cm}-1$ after cracking. We can also find that the absorption peaks related to phenyl and Si-CH3 absorption peak do not change after cracking. This indicates that the final product is MPCS. No obvious Si-OH absorption peak is found in the figure, meaning that the linear methyl phenyl polysiloxane has changed into ring siloxane.

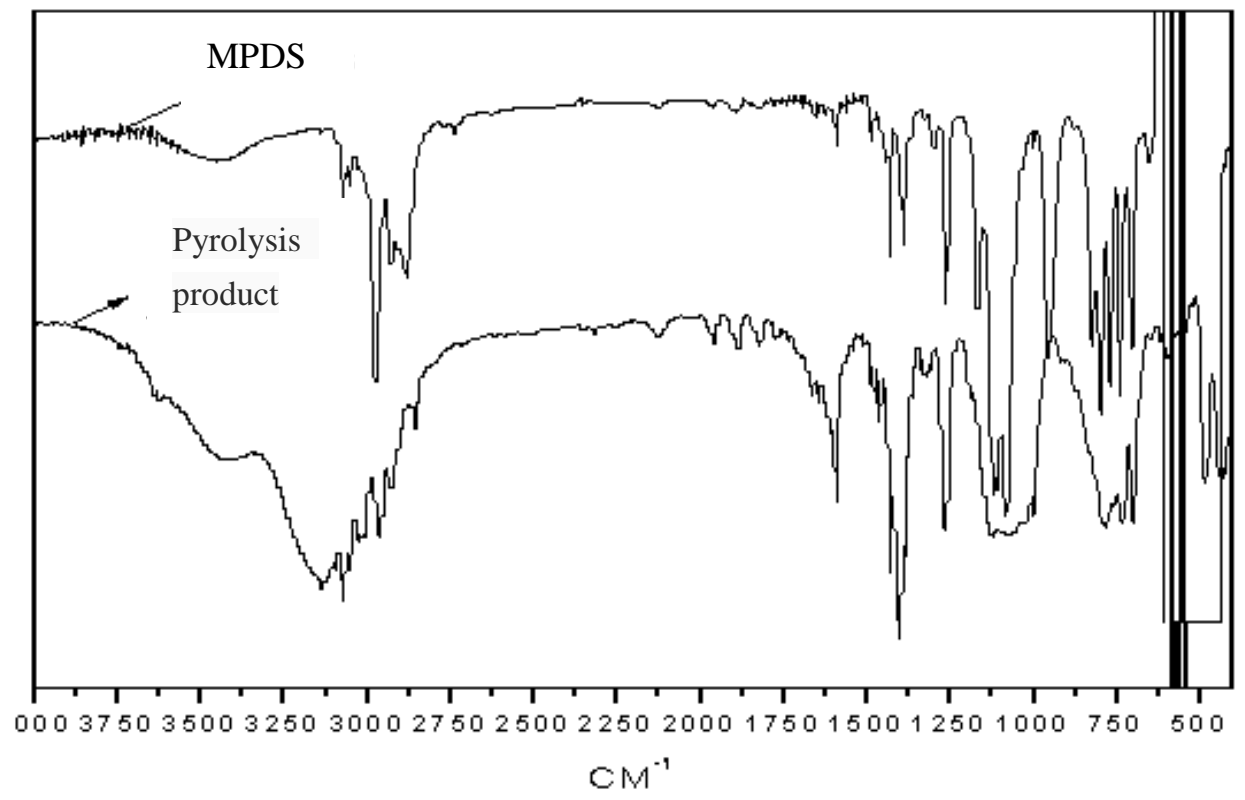

Fig.2 IR photograph of MPDS and pyrolysis product (MPCS)

\section{Conclusions}

The MPDS was synthesized by one step Grignard method. The optimal conditions were determined by orthogonal test method and the maximum MPDS yield of $60.2 \%$ was obtained at molar ratio of $\mathrm{Mg} / \mathrm{MTS} / \mathrm{CB} 1 / 1.5 / 1.25$, reaction time $2.5 \mathrm{~h}$ and reaction temperature $95^{\circ} \mathrm{C}$. Compared with those reported in literature, this method has some advantages, such as high yield, simple process and low energy consumption. The MPCS was synthesized with the prepared MPDS as raw material by hydrolysis and pyrolysis methods. The optimal conditions were determined by single factor method and the maximum MPCS yield of $72 \%$ was achieved with fractional addition of MPDS and DBS/MPDS mass ratio of $4 \%$ at $95^{\circ} \mathrm{C}$. The purity of MPCS is allowed to be lower than that of methyl phenyl dichlorosilane, which can benefit the realization of industrial production.The following work will focus on the preparations of methyl phenyl vinyl raw rubber and addition-cured liquid silicone rubber with the synthesized MPDS and MPCS as raw materials.

\section{Acknowledgement}

This subject was funded by the project in National Science \& Technology Pillar Program, China. (2014BAC04B02).

\section{References}

[1] Shao Qian, Yang Xiongfa, Haxilin, et al. Silicone Materia, 24(2010), p.316. 
[2] GRIGORIEVNA A, GOLUBTSOV S A, IVANOV V I.anes. U.S. Patent 35586(1971-01-26).

[3] Meijiang Li, Jianxiong Jiang, Guoqiao La. CN, Patent 101125860 ( 2008-02-20).

[4]Guoqiao, Lai, Meijiang Li, Jianxiong Jiang:lic silicone. CN, Patent 101503421( 2009-2-12).

[5] Fazhi Shen. New Chemical Materials, 37(2009), p.29.

[6]Jianxin Chen. Methods of Technology and formula. Hangzhou: Zhejiang Science and Technology Press, China, 1986. 